\title{
KAISER, Michael, KROLL, Stefan, Militär und Religiosität in der Frühen Neuzeit
}

\section{Anne Pérennec-Sublime}

\section{OpenEdition}

\section{Journals}

Édition électronique

URL : http://journals.openedition.org/ifha/878

DOI : $10.4000 /$ ifha. 878

ISSN : 2198-8943

\section{Éditeur}

IFRA - Institut franco-allemand (sciences historiques et sociales)

\section{Référence électronique}

Anne Pérennec-Sublime, « KAISER, Michael, KROLL, Stefan, Militär und Religiosität in der Frühen Neuzeit », Revue de l'IFHA [En ligne], Date de recension, mis en ligne le 01 janvier 2005, consulté le 22 septembre 2020. URL : http://journals.openedition.org/ifha/878 ; DOI : https://doi.org/10.4000/ifha 878

Ce document a été généré automatiquement le 22 septembre 2020.

(C)IFHA 


\title{
KAISER, Michael, KROLL, Stefan, Militär und Religiosität in der Frühen Neuzeit
}

\author{
Anne Pérennec-Sublime
}

L'ouvrage collectif dirigé par M.K. et St.K. est le résultat d'un colloque organisé par le groupe de recherche "Fait militaire et société à l'époque moderne " en mai 2002 à Göttingen. Ce colloque avait pour but de développer les recherches en histoire religieuse dans un domaine jusque-là laissé de côté : l'armée. Dans leur introduction, les deux éditeurs déplorent avec raison l'absence de toute étude globale sur le sujet, les armées et la société militaire ayant été définies par Anton Schindling comme des ensembles à la frontière des processus de confessionnalisation (dans un article sur la confessionnalisation et ses frontières, publié dans le volume de conclusion de la série sur les territoires du Reich à l'époque de la Réforme et de la confessionnalisation), et ayant donc été exclues des très nombreux travaux réalisés sur ce thème.

Les interventions - qui ne peuvent toutes être évoquées dans le cadre de ce compte rendu - se répartissent suivant quatre thèmes : le fait militaire et l'État, la propagande de guerre et le discours autour de la guerre, les ecclésiastiques et le domaine militaire, et enfin la mentalité religieuse des militaires.

À l'intérieur de ces thèmes, la plupart des communications portent sur la période consécutive aux traités de Westphalie, et beaucoup se concentrent sur le XVIIIe s., période pour laquelle les archives sont beaucoup plus importantes en raison de la formalisation et de l'organisation toujours plus stricte des armées. Les contributions concernent des territoires très divers, qui à de rares exceptions près (C. ZWIERLEIN s'intéresse à l'intervention papale dans les guerres de religion françaises) sont toujours situés dans le Saint-Empire. On peut ainsi dégager de l'ensemble des interventions quelques lignes directrices sur la place de la religion dans les armées modernes de l'espace germanique.

Dans son intervention, M. PLASSMANN souligne l'intérêt des Cercles d'Empire, à partir de l'exemple de celui de la Souabe, lieu de coexistence confessionnelle, qui a dû 
organiser ses armées en tenant compte de la religion des soldats. Il montre cependant que les troupes ne sont pas confessionnellement homogènes, mais qu'au contraire les postes d'officiers sont équitablement répartis et que des aumôniers des deux confessions sont prévus, afin de garantir aux soldats le libre exercice de leur religion.

Coorganisateur du colloque, St.K. s'est intéressé à la crainte de Dieu et au patriotisme comme ressorts de la discipline des soldats dans la Saxe électorale au XVIIIe s. Il ressort de son étude que la foi importe bien moins que le patriotisme, ce qui est également souligné par la plupart des contributions portant sur la propagande de guerre.

B. MARSCHKE utilise un corpus original pour étudier l'organisation pastorale de l'armée prussienne de Frédéric-Guillaume Ier : les archives du réseau piétiste de Halle lui permettent d'aborder l'aumônerie militaire sous l'angle de la bureaucratisation et de la formalisation du système pastoral, ce qui montre l'aspect essentiellement disciplinaire qu'a pu prendre la confessionnalisation dans l'armée.

Dans son ensemble, ce volume ouvre de nombreuses pistes, et illustre bien la diversité du fait religieux dans le Saint-Empire, ainsi que la multiplicité des structures militaires, ce qui rend difficile une vue d'ensemble tant territoriale que chronologique.

Anne PERENNEC-SUBLIME (Lycée Gabriel-Monod, Enghien-les-Bains) 